\title{
Using Tablets to Collect Breast Cancer Risk Information in an Underserved Population
}

\author{
Arash Naeim, David Geffen School of Medicine, UCLA, USA \\ Zhuoer Xie, David Geffen School of Medicine, UCLA, USA \\ Liliana Johansen, David Geffen School of Medicine, UCLA, USA \\ Neil S. Wenger, David Geffen School of Medicine, UCLA, USA \\ David Elashoff, David Geffen School of Medicine, UCLA, USA \\ Antonia Petruse, David Geffen School of Medicine, UCLA, USA \\ Guita Rahbar, Olive View-UCLA Medical Center, USA
}

\begin{abstract}
The authors tested the use of tablets to collect breast cancer risk data and compared the approach against paper-based scantrons. The goal was to examine the usability of digital technology for data collection in underserved populations. A total of 340 individuals were randomized to answer a breast health survey via either tablets (170) or paper forms (170). Post questionnaire surveys were conducted to evaluate the usability of tablets. Outcomes included completion time, satisfaction, and the numbers and types of questions raised by patients during the survey. There was no significant difference in questionnaire completion time between two groups (12.5 vs. 12.1 minutes, $\mathrm{p}=0.07$ ). The tablet group was more satisfied with the experience $(\mathrm{p}<0.001)$. Low health literacy women spent more time on the questionnaire $(\mathrm{p}<0.05)$. Electronic devices can be utilized to collect breast cancer risk data in underserved, ethnically diverse populations. Future healthcare questionnaire applications should focus on accessibility improvements for these populations.
\end{abstract}

\section{KEYWORDS}

Breast Cancer, Data Collection, Digital Health, Health Literacy, Risk Information, Underserved Population

\section{INTRODUCTION}

Digital technology has been a rapidly emerging field in clinical care over the past decade (Steinhubl, Muse, \& Topol, 2015). Previous work had shown the utility of electronic applications for various purposes such as collecting informed consent, gathering patient reported outcomes, assessing quality of life, providing medical education, delivering diagnostics, and filling out questionnaires (Abernethy et al., 2008). The advantages of data collection via electronic application include reduced costs in the long term, easier data storage, improved data quality, and guaranteed data consistency (Barentsz et al., 2014; Kumar et al., 2013; Lofland, Schaffer, \& Goldfarb, 2000). However, the emerging health care technologies may exacerbate the digital divide in certain patient populations (Arcaya \& Figueroa, 2017).

DOI: 10.4018/IJEHMC.20201001.oa1

This article published as an Open Access article distributed under the terms of the Creative Commons Attribution License (http://creativecommons.org/licenses/by/4.0/) which permits unrestricted use, distribution, and production in any medium, provided the author of the original work and original publication source are properly credited. 
Underserved populations (Silow-Carroll, Alteras, \& Stepnick, 2006) who are with limited health literacy, low in-income, elderly, racial and ethnic minorities are usually excluded from new health technology studies because they are unable to complete the study requirements, or lack interests in the studies (Chaudry, Connelly, Siek, \& Welch, 2012; M. S. Goel et al., 2011; Mita Sanghavi Goel et al., 2011; Hahn et al., 2004). Few previous studies have evaluated the use of digital health and electronic devices in such populations (Aiello et al., 2006; Bravo, O'Donoghue, Kaplan, Luce, \& Ozanne, 2014; Levy, Janke, \& Langa, 2015; Lin, Neafsey, \& Strickler, 2009; Sarkar et al., 2010; Vargas, Robles, Harris, \& Radford, 2010). Moreover, these populations may have a harder time learning to use the electronic devices and less likely to access the technology (Levy et al., 2015; Sarkar et al., 2010).

Without health technology, accurate and detailed data collection totally relies on paper forms. Paper based data collection requires significant additional time resources for manual data entry, which can be complicated and impractical for primary care providers in poorly-resourced health care systems (Qureshi et al., 2007). Studies showed that the time limitation of the office visit caused by comprehensive family and personal history collection led to low preventive service delivery rate, although US Preventive Services Task Force (USPSTF) and many national agencies provide guidelines to prevent chronic diseases and cancer (Yarnall, Pollak, Østbye, Krause, \& Michener, 2003).

Given the importance of family and personal history as predictors of cancer, efficient data collection is essential especially when the amount of provider-patient time is more limited. As breast cancer is the leading cancer diagnosis in Hispanic women ("Cancer Facts \& Figures for Hispanics/ Latinos 2015-2017," 2017), comprehensive personal and family risk factor information must be collected in order to stratify breast cancer risk (Murff, Byrne, Haas, Puopolo, \& Brennan, 2005; Rich et al., 2004). Therefore, it is critical to develop and test new information collection strategies to increase data collection efficiency, decrease physicians' workload in the busy clinics, and while ensuring patient satisfaction especially in underserved populations.

UCLA's Athena Breast Program is part of a statewide Athena Breast Health Network designed as a quality improvement initiative with the goals to design and test system-wide new approaches to research, technology and health care delivery (Elson et al., 2013). As part of that, this study was designed to collect breast cancer risk information through mobile electronic devices and compare it with paper-based scantron forms via a randomized trial. The hypothesis was that the digital technology might be difficult for underserved populations. Therefore, the usability of the tablet-driven data collection method in an underserved county population was examined and the impact of health literacy level, primary language (Spanish or English) and age on the usability were investigated.

This research study is novel in that it contributes to the limited research around collecting breast cancer risk stratification data (family and personal history) electronically in an under-served and under-represented population. Precision medicine relies on digital data and innovations in the use of technology, the use of which in low literacy populations requires thoughtful consideration.

This paper is organized as follows. In the Methods section, we define the population, the clinical trial design, the outcome measurements and the statistical methods. In the Results section, we demonstrate our findings. In the Conclusion section, we discuss our work and make conclusions based on our results. Finally, we summarize our finding and future works.

\section{METHODS}

\section{Population}

The Olive View-UCLA Medical Center (OVMC) is a Los Angeles County Department of Health Services hospital, serving a diverse ethnicity, low income population in San Fernando Valley. OVMC participated in the Athena Breast Health Network quality improvement effort to collect information at the time of breast cancer screening for breast cancer risk assessment (Elson et 
al., 2013). Women presenting for mammogram screening were eligible if their primary language was English or Spanish and they had no history of breast cancer. Of 703 women who presented to OVMC for breast screening mammography in a 5-month period, as part of the broader 5-year statewide Athena registry project from 2010-2015, 340 (48.4\%) consented to participate in this study. Of the 363 women who declined, 358 refused due to time limitations or lack of interests in the study, and 5 did not speak English or Spanish. Institutional review board (IRB) obtained from UCLA-OVMC approved the study.

\section{Randomization of Data Collection Modalities}

Using Excel random number generator, participants who consented were randomly assigned in a 1:1 ratio to either a Tablet questionnaire group (Tablet group) or a Paper-based Scantron questionnaire group (Paper group). A total of 340 women were randomly assigned into the two arms (Figure 1). Participants were encouraged to complete the questionnaire using the format

Figure 1. Workflow for data collection randomization

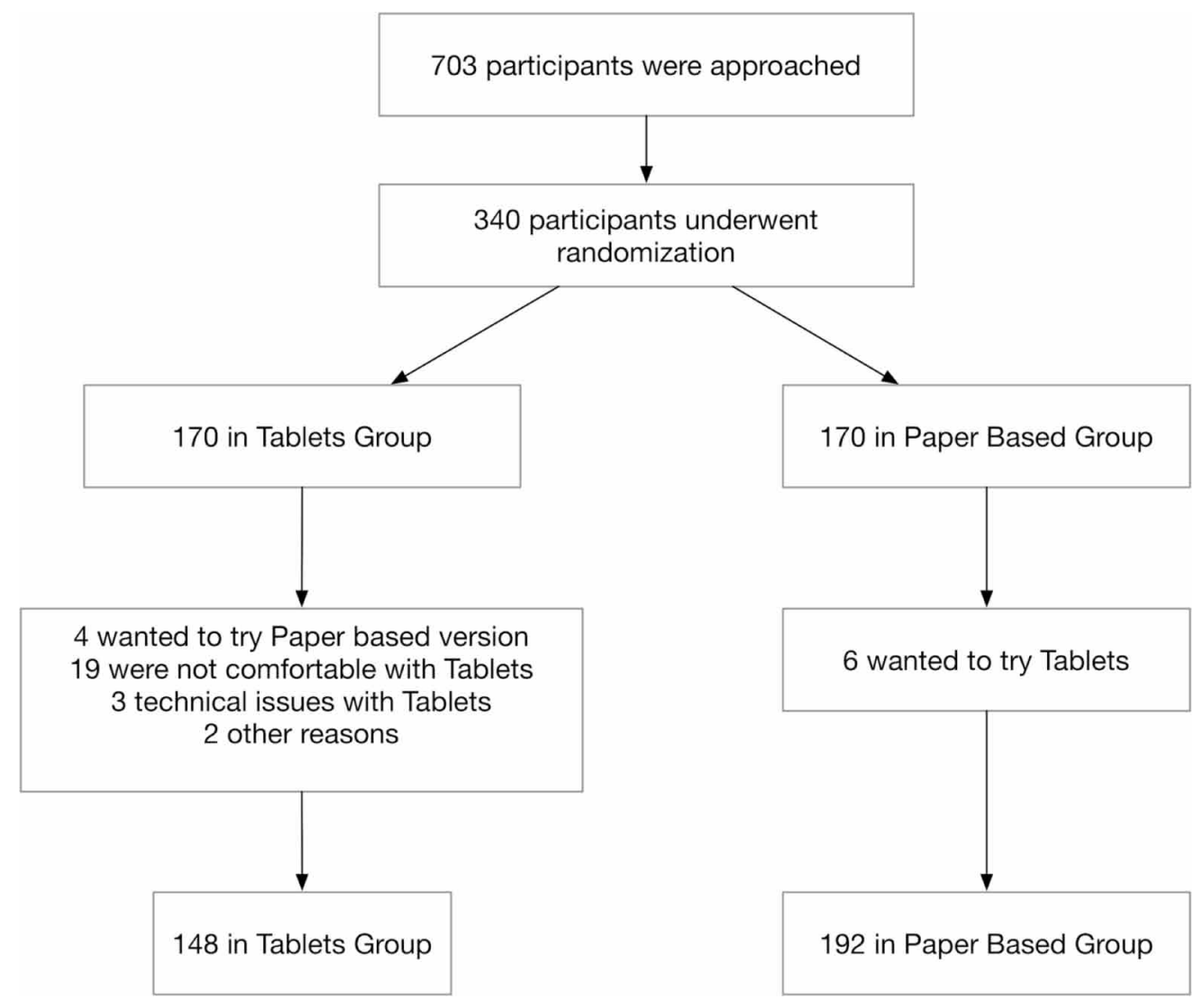

to which they were assigned. If a participant experienced difficulty using a modality, she could switch to the other in order to ensure the breast cancer risk information to be collected, since the goal of Athena Breast Health Network is to collect data and provide individualized risk stratification strategy. 


\section{Athena Breast Health Paper Questionnaire and Electronic Questionnaire Development}

The paper-based Scantron Athena Breast Health Questionnaire (ABHQ; Bravo et al., 2014) was adapted from the San Francisco Mammography Registry. Figure 2 shows the paper-based ABHQ page 1. Considering the Spanish speaking populations, a Spanish ABHQ version was generated by

Figure 2. Athena breast health questionnaire, paper form page 1

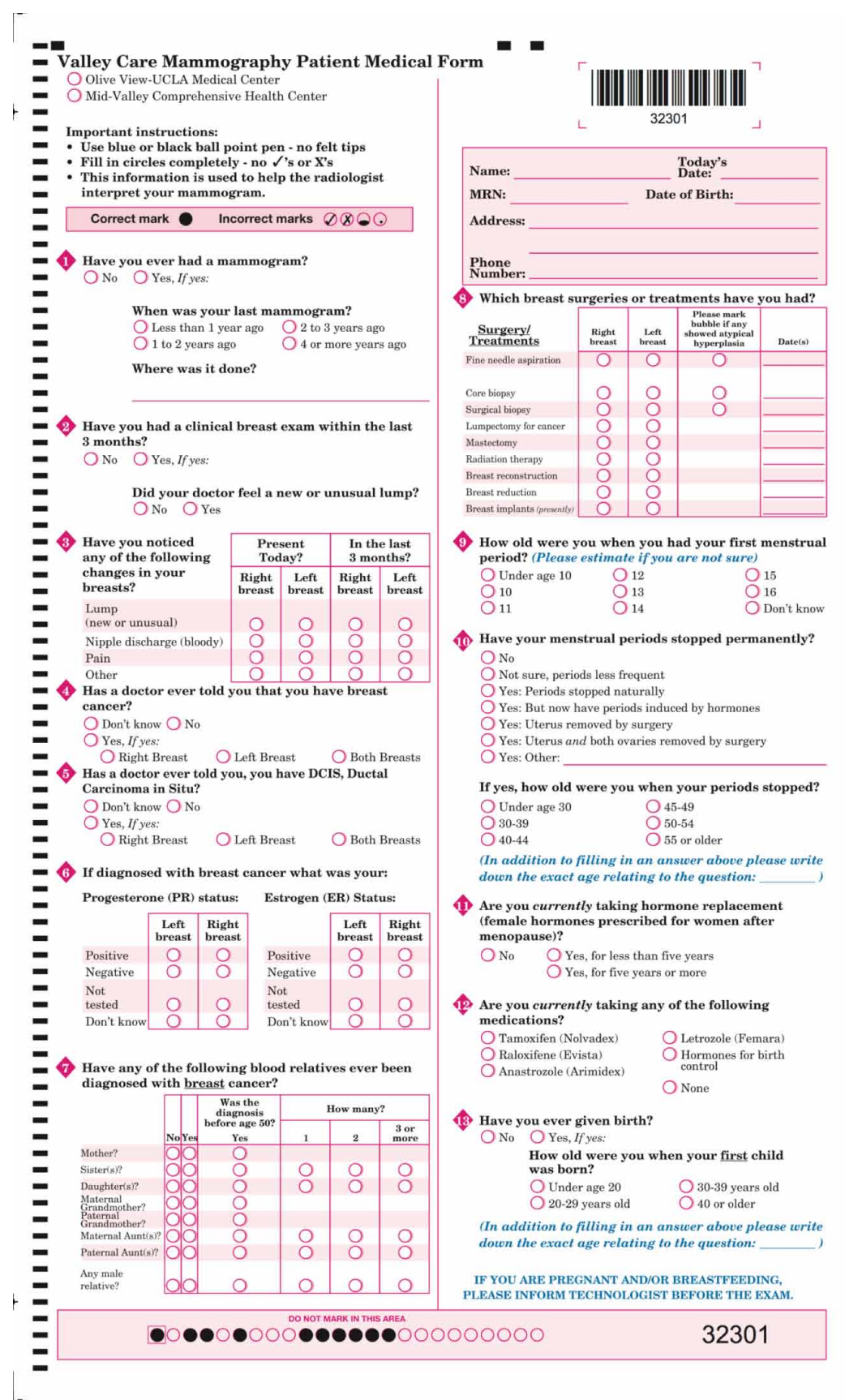


an official certified Spanish translator and it was reviewed and approved by Athena Breast Health community advisory board. The ABHQ captured data on personal health, sociodemographic, and education level. USPSTF high risk model was embedded in the ABHQ.

The electronic ABHQ (E-ABHQ) was developed as a tablet application on iOS platform by Athena Breast Health Network. Its content was the same as the paper-based form. The app presents one question at a time. At the bottom of the screen, the "Previous" and "Next" buttons were available to navigate between questions. If the choices for one question occupy more than one screen, "scroll up and down for more choices" were shown to remind participants to browse all available options. Figure 3 shows the screenshots of the E-ABHQ application.

\section{Questionnaire Administration and Post-Questionnaire Survey}

In the mammogram clinic, a bilingual (Spanish-English) research staff approached one woman at a time and consented them separately in a private conference room located in the radiology department.

Figure 3. Athena breast health questionnaire, tablet form screenshots

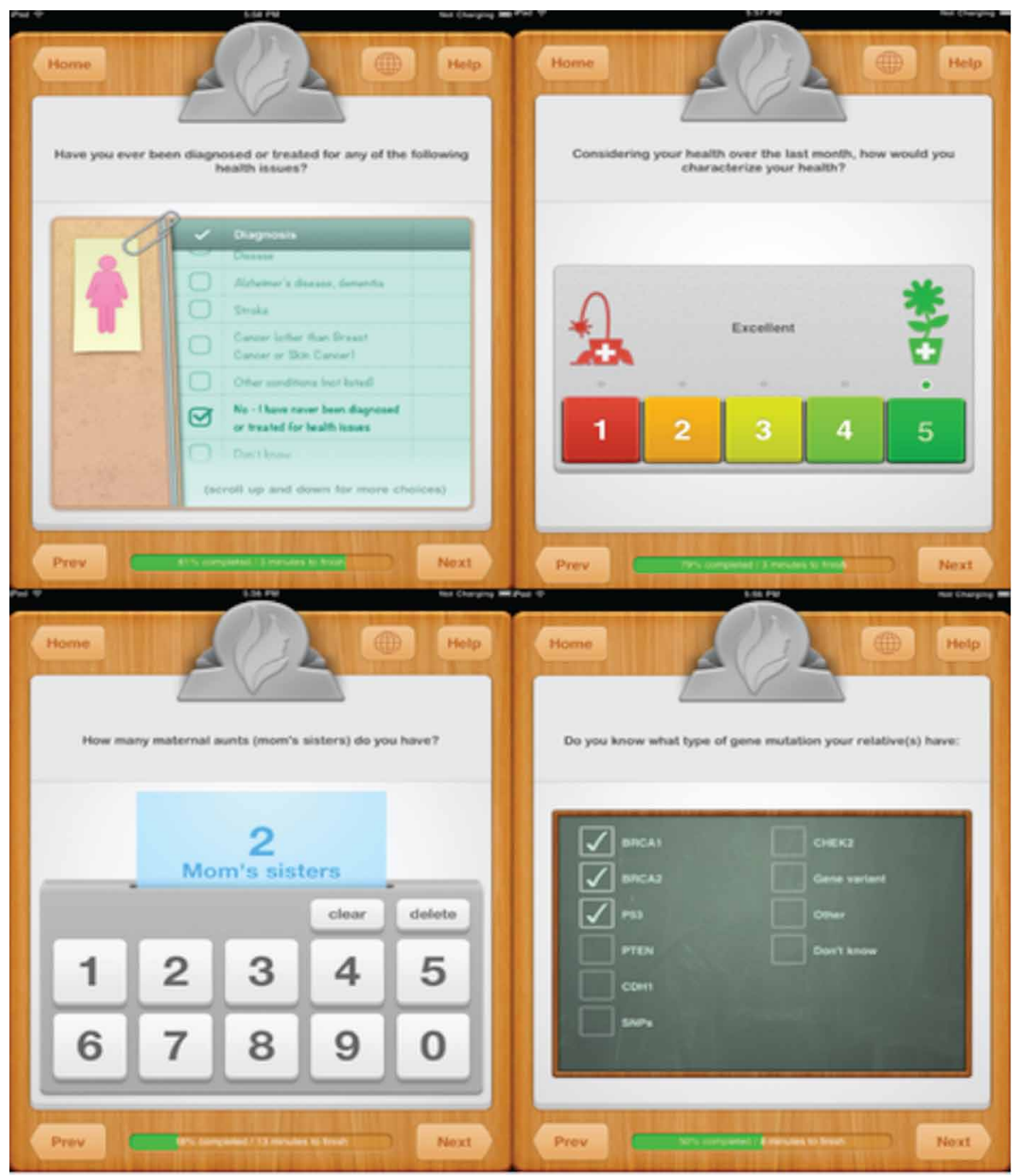


Women who agreed to participate in the study were brought back to the waiting area to finish the ABHQ and a post ABHQ survey while waiting for the mammogram.

The research staff accompanied participants throughout the ABHQ and the survey process. If participants were called for mammogram during the process, the research staff would inform the radiology department that participants had not finished so to ensure no interruptions during the process. Participants could communicate with the research staff if any questions arose. The questions were recorded and used for usability evaluation.

Women could choose either an English or Spanish version of the ABHQ based on their language preference. The post ABHQ survey was also available in both languages to collect their sociodemographic data (race, preferred language, and education level), past experience with information technology and health literacy level. Education levels were defined as "some high school or less", "high school graduate", "some college or technical school" and "college graduation or more". Information technology experience was assessed by questions: "Do you use a computer?" "Do you use a cellphone?" "Do you use email?" and "Do you use the internet?". Health literacy (HL) was assessed using the short version of the Test of Functional Health Literacy in Adults (S-TOFHLA) and was categorized into "inadequate HL", "marginal HL", and "adequate HL" based on S-TOFHLA scores of 0-16, 17-22 and 23-36, respectively (Baker, Williams, Parker, Gazmararian, \& Nurss, 1999). The English and Spanish S-TOFHLA were compared together since validation studies of the English and Spanish S-TOFHLA have found similar performance (Lee, Bender, Ruiz, \& Cho, 2006; Sarkar, Schillinger, López, \& Sudore, 2011).

\section{Outcome Measures}

The following information about ABHQ and E-ABHQ to evaluate the usability of E-ABHQ were collected: (1) questionnaire completion; (2) crossover from Tablet to Paper and vice-versa, and the reasons; (3) the number of missing responses; (4) the number of questions arisen by participants (these questions were categorized into three types, i.e. questions about the technology, questions about the questionnaire contents, and questions about personal information (Table 2), then the number of each type was recorded); (5) completion time recorded by two research staffs as the time span between when the questionnaire was handed to participants and when they were returned; and (6) patient satisfaction measured in the post ABHQ survey by the question "How did you like answering the ABHQ" with choices "not very much", "indifferent", "liked a little" and "liked a lot" coded in a four-point scale.

\section{Statistics and Data Analysis}

The usability of E-ABHQ was analyzed through comparing outcome measurements between groups using tablets and paper-based forms. Analyses were conducted on both the intention-to-treat (ITT) basis and as delivered basis. The results based on ITT (170 in each arm) were reported. Power analysis was not conducted as this is part of Athena Breast Health Quality Improvement project.

First, demographic characteristics and basic completion information were compared between groups using Chi square tests (gender, race, education level, HL level, preferred language, questionnaire completion) and t-tests (age, S-TOPHLA score). Then the completion time, which was considered as the most direct indicator of usability, was compared between groups using two sample t-tests. Following that, the count of missing responses, the number of participants' questions, and number of questions in each question type (technical, content, and personal), were compared between groups with Poisson regression. Participant satisfaction was compared between groups with a Wilcoxon rank sum test. Additionally, in order to investigate the impacts of HL, language and age on the usability, the entire cohort was further stratified by HL level, language and age respectively. After that, the completion time, satisfaction, and the number of questions were compared between subgroups using regression (linear for completion time and satisfaction; Poisson for the question counts). 
Linear regression was used to examine predictors of completion time. Predictors included: group, age, education, S-TOPHLA score, HL score, language, and the questions counts. Since the number of different types of questions may be a mediator of the effects of social/demographic characteristics on completion time, a mediation analysis was performed (Emsley, Liu, Emsley, \& Liu, 2013). Using the subset of variables that were significant on the single variable regression analyses (excluding the mediators), a forward stepwise variable selection was used to fit a multiple regression model.

Two-sided $\mathrm{p}$ values were reported and variables were considered statistically significant if the p-value $<0.05$. All analyses were preformed using STATA 15 .

\section{RESULTS}

The participants' mean age was 51.4 years $(\mathrm{SD}=8.7)$, and $82 \%$ were Latina. There were 259 participants whose primary language was Spanish. Among these 259 participants, 105 were bilingual and they answered $\mathrm{ABHQ} / \mathrm{E}-\mathrm{ABHQ}$ in English. Although the vast majority used a cellphone (>80\%), less than 50\% used computers, email, or the internet. Almost 50\% had less than a high school education. The average S-TOFHLA score was $23.5(\mathrm{SD}=10)$ and $55 \%$ had scores categorized as inadequate HL (Table 1).

\section{Form Completion and Switching Between Tablet and Paper-Based Form}

All participants completed the questionnaire and there was no difference in the number of missing responses between the Tablet and Paper groups (median $1 \mathrm{v} 1$, respectively, $\mathrm{p}=0.43$ ). About half participants answered all the questions, 20\% had 2-3 responses missing and the rest of them had more than 3 missing responses. The number of missing responses didn't differ between subgroup analyses on age, health literacy or language. Twenty-eight (16.5\%) participants in the Tablet group switched to Paper; 19 (68\%) felt using a tablet uncomfortable; $4(14 \%)$ wanted to try Paper-based form; 3 (11\%) had technical issues (i.e., the WIFI device used by the research team ran out of battery, slow application); and 2 (7\%) due to poor vision. Six (3.5\%) participants randomized to Paper switched to Tablet $(\mathrm{p}<0.001)$ with the reason of "wanted to try a tablet".

\section{Number of Questions Asked by Participants}

Participants in the Tablet group asked more questions to the coordinator about navigating the process than the Paper group (median 3 v 2, $\mathrm{p}<0.001$ ). This difference was primarily due to the number of technical questions (median $1 \vee 0, p<0.001$ ). The number of content questions and personal questions were similar between the two groups (median of content questions in Tablet $=1 \mathrm{v}$ Paper $=1, \mathrm{p}=0.4$; median of personal questions in Tablet $=0 \mathrm{v}$ Paper $=0, \mathrm{p}=0.9$ ) (Table 3).

Across the three HL levels, each level has more technology questions in the Tablet group than the Paper-based group. In the tablet group, the number of technology questions was related to HL, but the numbers of content and personal questions were not (Table 4). Participants who completed the $\mathrm{ABHQ} / \mathrm{E}-\mathrm{ABHQ}$ in Spanish had more content questions, whereas there were no significant differences in the number of technical or personal questions regardless of the primary language (Table 5). The number of questions didn't different by age strata. (Data are not shown).

\section{Completion Time}

The mean time to complete the questionnaire was $12.5(\mathrm{SD}=3.1)$ minutes in the Tablet group v 12.1 $(\mathrm{SD}=2)$ minutes in the Paper group $(\mathrm{p}=0.07)$ (Table 3). The difference between groups was not significantly related to HL level (Table 4) or age. However, completion time was significantly longer in Spanish speaking group (Paper group: Spanish 12.3 minutes v English 11.4 minutes, p=0.003; Tablet group: Spanish 12.8 minutes v English 11.6 minutes, $p=0.02$; Table 5). Low HL participants 
Table 1. Sociodemographic and health status characteristics of participants

\begin{tabular}{|c|c|c|}
\hline & Tablet & Paper \\
\hline Number of participants & 170 & 170 \\
\hline Age, mean $(\mathrm{SD})^{*}$ & $50.4(9.2)$ & $52.3(8.6)$ \\
\hline \multicolumn{3}{|l|}{ Race/Ethnicity } \\
\hline White & $11 \%$ & $8 \%$ \\
\hline Hispanic & $81 \%$ & $83 \%$ \\
\hline African American & $1 \%$ & $2 \%$ \\
\hline Asian & $1 \%$ & $2 \%$ \\
\hline Other & $6 \%$ & $5 \%$ \\
\hline \multicolumn{3}{|l|}{ Primary Language } \\
\hline English & $23 \%$ & $25 \%$ \\
\hline Spanish & $77 \%$ & $75 \%$ \\
\hline \multicolumn{3}{|l|}{ Technology Use } \\
\hline Cell Phone* & $89 \%$ & $79 \%$ \\
\hline Computer & $44 \%$ & $36 \%$ \\
\hline Email & $38 \%$ & $30 \%$ \\
\hline Internet & $42 \%$ & $32 \%$ \\
\hline \multicolumn{3}{|l|}{ Education Level } \\
\hline Less than High School Grad & $45 \%$ & $49 \%$ \\
\hline High School Grad & $21 \%$ & $23 \%$ \\
\hline Some College & $18 \%$ & $18 \%$ \\
\hline College Grad & $15 \%$ & $9 \%$ \\
\hline No Response & $1 \%$ & $1 \%$ \\
\hline S-TOFHLA score (SD) & $24.3(10)$ & $22.8(10)$ \\
\hline \multicolumn{3}{|l|}{ Health Literacy } \\
\hline Adequate & $47 \%$ & $44 \%$ \\
\hline Marginal & $18 \%$ & $11 \%$ \\
\hline Inadequate & $22 \%$ & $31 \%$ \\
\hline
\end{tabular}

SD = standard deviation, S-TOFHLA: Short Version of the Test of Functional Health Literacy in Adults

${ }^{*} \mathrm{p}<.05$ between Tablets and Scantron groups

\section{Table 2. Examples of questions based on three categories}

\begin{tabular}{|l|l|l|}
\hline \multirow{2}{*}{$\begin{array}{l}\text { Technology } \\
\text { Questions }\end{array}$} & Tablet & How to scroll down the page? \\
\cline { 2 - 3 } & Paper & $\begin{array}{l}\text { Whether to bubble or check the options. } \\
\text { Font sizes were too small. }\end{array}$ \\
\hline \multirow{2}{*}{ Content Questions } & $\begin{array}{l}\text { What is DCIS? } \\
\text { What is clinical breast exam? } \\
\text { What is estrogen and progesterone status? }\end{array}$ \\
\hline Personal Questions & $\begin{array}{l}\text { Cannot remember the family history. } \\
\text { Cannot remember whether uterus or ovaries were removed. } \\
\text { Date of the last mammogram. }\end{array}$ \\
\hline
\end{tabular}


Table 3. Overall outcome comparison between tablet and paper groups

\begin{tabular}{|l|l|l|l|}
\hline & \multicolumn{1}{|c|}{$\begin{array}{c}\text { Tablet } \\
\text { Median (IQR) }\end{array}$} & \multicolumn{1}{|c|}{$\begin{array}{c}\text { Paper } \\
\text { Median (IQR) }\end{array}$} & \multicolumn{1}{|c|}{ P Value } \\
\hline Completion Time & $12.5(3.1)$ & $12.1(2)$ & 0.07 \\
\hline Missing Responses & $1(0-1)$ & $1(0-1)$ & 0.43 \\
\hline Total Questions & $3(1-4)$ & $2(1-3)$ & $<0.001$ \\
\hline Technology Questions & $1(0-2)$ & $0(0-1)$ & $<0.001$ \\
\hline Content Questions & $1(0-2)$ & $1(0-2)$ & 0.35 \\
\hline Personal Questions & $0(0-1)$ & $0(0-1)$ & 0.89 \\
\hline Satisfaction & $3(2-3)$ & $2(0-3)$ & $<0.001$ \\
\hline
\end{tabular}

apresented as mean (SD); IQR: interquartile range (IQR, 25th-75th percentile)

Table 4. Outcome comparison by health literacy level between groups and within groups

\begin{tabular}{|c|c|c|c|}
\hline & $\begin{array}{c}\text { Tablet } \\
\text { Median (IQR) }\end{array}$ & $\begin{array}{c}\text { Paper } \\
\text { Median (IQR) }\end{array}$ & $P$ Value \\
\hline $\begin{array}{l}\text { Completion Time } \\
\text { Adequate HL } \\
\text { Marginal HL } \\
\text { Low HL } \\
\text { P value for the trend }(\beta)\end{array}$ & $\begin{array}{l}12(2.8) \\
12.3(2.5) \\
13.7(4) \\
0.01(-0.84)\end{array}$ & $\begin{array}{l}11.7(1.9) \\
11.6(1.8) \\
12.7(2.2) \\
0.01(-0.47)\end{array}$ & $\begin{array}{l}0.27 \\
0.16 \\
0.06\end{array}$ \\
\hline $\begin{array}{l}\text { Technology Questions } \\
\text { Adequate HL } \\
\text { Marginal HL } \\
\text { Low HL } \\
\text { P value for the trend (IRR) }\end{array}$ & $\begin{array}{l}1(0-2) \\
1(0-2) \\
2(1-3) \\
<0.001(0.74)\end{array}$ & $\begin{array}{l}0(0-1) \\
0(0-0) \\
0(0-1) \\
0.28(1.17)\end{array}$ & $\begin{array}{l}<0.001 \\
<0.001 \\
<0.001\end{array}$ \\
\hline $\begin{array}{l}\text { Content Questions } \\
\text { Adequate HL } \\
\text { Marginal HL } \\
\text { Low HL } \\
\text { P value for the trend (IRR) }\end{array}$ & $\begin{array}{l}1(0-1) \\
1(0-1) \\
1(1-2) \\
<0.001(0.68)\end{array}$ & $\begin{array}{l}1(0-2) \\
1(0-2) \\
1(0.5-2) \\
0.01(0.81)\end{array}$ & $\begin{array}{l}0.29 \\
0.73 \\
0.33\end{array}$ \\
\hline $\begin{array}{l}\text { Personal Questions } \\
\text { Adequate HL } \\
\text { Marginal HL } \\
\text { Low HL } \\
\text { P value for the trend (IRR) }\end{array}$ & $\begin{array}{l}0(0-1) \\
0(0-1) \\
0(0-1) \\
0.71(0.95)\end{array}$ & $\begin{array}{l}0(0-1) \\
0(0-1) \\
1(0-1.5) \\
<0.001(0.66)\end{array}$ & $\begin{array}{l}0.2 \\
0.1 \\
0.06\end{array}$ \\
\hline $\begin{array}{l}\text { Total Questions } \\
\text { Adequate HL } \\
\text { Marginal HL } \\
\text { Low HL } \\
\text { P value for the trend (IRR) }\end{array}$ & $\begin{array}{l}2(1-3) \\
3(1-5) \\
4(2-5) \\
<0.001(0.76)\end{array}$ & $\begin{array}{l}2(0-3) \\
2(0-3) \\
3(1-4) \\
0.001(0.82)\end{array}$ & $\begin{array}{l}0.02 \\
0.003 \\
<0.001\end{array}$ \\
\hline $\begin{array}{l}\text { Missing Responses } \\
\text { Adequate HL } \\
\text { Marginal HL } \\
\text { Low HL } \\
\text { P value for the trend (IRR) }\end{array}$ & $\begin{array}{l}0.5(0-1) \\
1(0-1) \\
1(0-1) \\
0.09(1.19)\end{array}$ & $\begin{array}{l}1(0-2) \\
0.5(0-1) \\
0(0-1) \\
0.42(1.08)\end{array}$ & $\begin{array}{l}0.35 \\
0.76 \\
0.79\end{array}$ \\
\hline $\begin{array}{l}\text { Satisfaction } \\
\text { Adequate HL } \\
\text { Marginal HL } \\
\text { Low HL } \\
\mathrm{P} \text { value for the trend }(\beta)\end{array}$ & $\begin{array}{l}3(3-3) \\
3(2-3) \\
3(2-3) \\
0.35(0.06)\end{array}$ & $\begin{array}{l}3(0-3) \\
3(2-3) \\
2(2-3) \\
0.82(0.01)\end{array}$ & $\begin{array}{l}<0.001 \\
0.77 \\
0.04\end{array}$ \\
\hline
\end{tabular}

HL: Health Literacy; IRR: incidence rate ratio; $\beta$ : regression coefficient; a presented as mean (SD) 
Table 5. Outcome by preferred language in two groups

\begin{tabular}{|l|l|l|l|l|l|l|}
\hline \multirow{2}{*}{} & \multicolumn{3}{|c|}{ Tablet Median (IQR) } & \multicolumn{3}{c|}{ Paper Median (IQR) } \\
\cline { 2 - 7 } & \multicolumn{1}{|c|}{$\begin{array}{c}\text { Spanish } \\
\text { N:131 }\end{array}$} & $\begin{array}{c}\text { English } \\
\text { N:39 }\end{array}$ & \multicolumn{1}{|c|}{$\mathbf{p}$ Value } & $\begin{array}{c}\text { Spanish } \\
\text { N:128 }\end{array}$ & $\begin{array}{c}\text { English } \\
\text { N:42 }\end{array}$ & p Value \\
\hline Technology Questions (No.) & $1(0-2)$ & $1(0-2)$ & 0.05 & $0(0-1)$ & $0(0-1)$ & 0.35 \\
\hline Content Questions (No.) & $1(0-2)$ & $0(0-1)$ & $<0.001$ & $1(1-2)$ & $0(0-1)$ & $<0.001$ \\
\hline Personal Questions(No.) & $0(0-1)$ & $0(0-1)$ & 0.89 & $0(0-1)$ & $0(0-1)$ & 0.1 \\
\hline Total Questions (No.) & $3(1-5)$ & $2(1-3)$ & $<0.001$ & $2(1-3)$ & $1(0-3)$ & $<0.001$ \\
\hline Missing Responses (No.) & $1(0-1)$ & $0(0-1)$ & 0.05 & $1(0-1)$ & $1(0-1)$ & 0.19 \\
\hline Completion Time (Minutes) & $12.8(3.2)$ & $11.6(2.6)$ & 0.02 & $12.3(2)$ & $11.4(2)$ & 0.003 \\
\hline Satisfaction (Score) & $3(2-3)$ & $3(3-3)$ & 0.56 & $2(0-3)$ & $2(0-3)$ & 0.68 \\
\hline
\end{tabular}

${ }^{a}$ presented as mean (SD)

spent longer time to finish the questionnaire (Tablet $\mathrm{p}=0.01$, regression coefficient $=-0.84$; Paper $\mathrm{p}=0.01$, regression coefficient $=-0.47$ ).

Univariable linear regression in the entire cohort found that all sociodemographic variables were predictors for the completion time (all $\mathrm{p}<0.05)$ except age that didn't reach a statistical significant level $(\beta=0.03, p=0.06)$ (Table 6). Univariable linear regression within each arm showed similar results as the entire cohort. In the mediation analysis, total questions and technology questions were found as mediators for the completion time ( $\mathrm{p}=0.002$ and $\mathrm{p}<0.001$ respectively). Based on this, they were not included in the final multivariable linear regression model. Finally, in the forward stepwise multivariable model, S-TOFHLA score was identified as a predictor for the completion time ( $\beta=-$ $0.06, \mathrm{p}<0.001)$ (Table 6).

Table 6. Univariable and multivariable models for $A B H Q$ completion time, entire cohort

\begin{tabular}{|c|c|c|c|c|}
\hline \multirow[b]{2}{*}{ Variable } & \multicolumn{2}{|c|}{ Univariable Regression } & \multicolumn{2}{|c|}{ Forward Stepwise Multivariable Regression } \\
\hline & 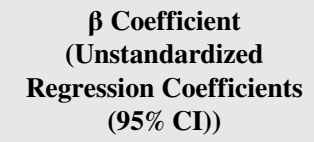 & p Value & $\begin{array}{c}\beta \text { Coefficient (Unstandardized } \\
\text { Regression Coefficients (95\% CI)) }\end{array}$ & p Value \\
\hline $\begin{array}{l}\text { Tablet/Paper } \\
\text { (fixed variable) }\end{array}$ & $0.42(-0.13,0.98)$ & 0.14 & $0.5(-0.1,1.1)$ & 0.1 \\
\hline Age & $0.03(-0.002,0.6)$ & 0.06 & unselected & \\
\hline Education & $-0.3(-0.59,-0.06)$ & 0.02 & unselected & \\
\hline S-TOPHLA & $-0.1(-0.09,-0.03)$ & $<0.001$ & $-0.06(-0.09,-0.03)$ & $<0.001$ \\
\hline Health Literacy & $-0.6(-0.98,-0.3)$ & $<0.001$ & unselected & \\
\hline Spanish/English & $1.1(0.4,1.7)$ & 0.001 & unselected & \\
\hline $\begin{array}{l}\text { Technology } \\
\text { Questions }\end{array}$ & $0.7(0.4,1)$ & $<0.001$ & unselected & \\
\hline Content Questions & $0.8(0.6,1)$ & $<0.001$ & unselected & \\
\hline Personal Questions & $0.4(0.1,0.8)$ & 0.01 & unselected & \\
\hline Total Questions & $0.48(0.3,0.6)$ & $<0.001$ & unselected & \\
\hline
\end{tabular}




\section{Satisfaction}

Participants in the Tablet group were more satisfied with the experience than the Paper-based group (median satisfaction score Tablet $=3 \mathrm{v}$ Paper $=2, \mathrm{p}<0.001$ ). In the Tablet group, the satisfaction didn't differ by age. But in the Paper-based group, older people ( $>=65$ years) were less satisfied. Within each arm, the satisfaction did not differ by HL level or language, but both adequate and low HL participants preferred to use Tablets (Tables 4 and 5).

\section{DISCUSSION AND CONCLUSION}

The goal of this novel clinical trial was to investigate the usability of tablets to collect comprehensive personal and family history that can be used to identify individuals at higher risk to develop breast cancer data in underserved populations. We found both Tablet and Paper-based forms were equally usable for this purpose. Participants in both groups finished the questionnaire in an efficient time manner, but in both groups lower health literacy posed additional challenges. This contributes to the limited literature in this area as current large-scale risk stratification data collection studies often lack adequate representation of under-representation populations.

Our study complements Chesser et al.'s work where they found that there was no difference on STOPHLA score when it was evaluated by both "paper" and "computer" on an adequate health literacy population in a randomized crossover study(Chesser, Keene Woods, Wipperman, Wilson, \& Dong, 2014). In our study, low HL participants had more questions about navigating the app and understanding the content of the ABHQ. Spanish speaking participants had more questions likely because many of the Spanish speaking participants had inadequate HL level. Low HL and Spanish speaking women also required more time to complete the survey. Our study identified similar challenges as previous studies, such as navigating the pages, scrolling, inputting nonnumeric words and understanding technical language (Medhi, Gautama, \& Thies, 2011). In line with previous studies, our study showed that it was harder and more time consuming for older patients to finish a questionnaire (Fromme, Kenworthy-Heinige, \& Hribar, 2011). Although it is encouraging that participants finished the E-ABHQ efficiently in the busy mammography department, our findings indicated that "at your elbow" assistance was essential for questionnaire completion for low HL populations.

Although low HL patients needed more assistance and spent approximately one to two more minutes to finish the questionnaire, their preference towards the electronic questionnaire was similar as the higher health literacy education level groups (Aiello et al., 2006; Barentsz et al., 2014). It was found that technology issues with tablets (e.g. navigation of the questionnaire) had a large impact on the questionnaire completion time for low HL participants. The barriers could be overcome if the technology is well designed to be practically useful, that is, intuitive and accessible, especially for patients who are less familiar with computer or tablet technology.

The technology design could be improved for low HL with bigger widgets (Chaudry et al., 2012), extensive graphical cues, looped voice instructions, simple navigation icons, limited nonnumeric text input and scrolling menus (Medhi et al., 2011). In this study, additional improvements were recommended in the future design to expand and enhance patients' engagement: (1) step-by-step guided instructions on each screen, (2) images to avoid confusion, (3) uniformed format of choices (i.e. limited choices to yes or no; checking boxes, etc.), (4) help icons on each question to explain medical concepts (e.g. DCIS, clinical breast exam, etc.), (5) a speech recognition function, (6) largefont questions and instructions, or text-to-speech functions for patients with poor vision, (7) a multilanguage option that could broaden the modality to a larger population.

There are several limitations in our study. First, in order to compare Tablet and Paper-based form equally, some Tablet functions that couldn't be realized in paper were limited, for example, drop-down lists. The tablet might be easier to use if more functions were adopted. Second, the questionnaire completion time was measured manually by research staff and this time was used to reflect the actual completion time. This might not be as precise as a timer embedded in the application. Third, 
the technology questions compared between groups were not the same, i.e. one group had questions about tablet technology, the other about paper form technology (checking and bubbling the answers). Fourth, all the patients are from OVMC, a Los Angeles county hospital, this may not represent a diverse population. Last, this study reported statistics about the questionnaire completion process, but it did not report the correctness of data collected or the outcome on breast cancer screening. Despite these limitations, our study significantly adds to current technology adoption, identifies challenges on the usage of mobile apps and provides implication on future application design strategies for the low health literacy populations.

In conclusion, the usability of the tablet-driven data collection method is comparable with the traditional paper-based Scantron forms in an underserved county population. The literacy issues need to be considered in the design and implementation of those approaches. Our future research is to further improve the usability of E-questionnaires with balanced features and complexity of an application in the low health literacy populations (Table 1). 


\section{REFERENCES}

Abernethy, A. P., Herndon, J. E. II, Wheeler, J. L., Patwardhan, M., Shaw, H., Lyerly, H. K., \& Weinfurt, K. (2008). Improving health care efficiency and quality using tablet personal computers to collect research-quality, patient-reported data. Health Services Research, 43(6), 1975-1991. doi:10.1111/j.1475-6773.2008.00887.x PMID: 18761678

Aiello, E. J., Taplin, S., Reid, R., Hobbs, M., Seger, D., Kamel, H., Tufano, J., \& Ballard-Barbash, R. (2006). In a randomized controlled trial, patients preferred electronic data collection of breast cancer risk-factor information in a mammography setting. Journal of Clinical Epidemiology, 59(1), 77-81. doi:10.1016/j.jclinepi.2005.07.007 PMID:16360564

Arcaya, M. C., \& Figueroa, J. F. (2017). Emerging Trends Could Exacerbate Health Inequities In The United States. Health Affairs, 36(6), 992-998. doi:10.1377/hlthaff.2017.0011 PMID:28583956

Baker, D. W., Williams, M. V., Parker, R. M., Gazmararian, J. A., \& Nurss, J. (1999). Development of a brief test to measure functional health literacy. Patient Education and Counseling, 38(1), 33-42. doi:10.1016/S07383991(98)00116-5 PMID:14528569

Barentsz, M. W., Wessels, H., van Diest, P. J., Pijnappel, R. M., Haaring, C., van der Pol, C. C., Witkamp, A. J., van den Bosch, M. A., \& Verkooijen, H. M. (2014). Tablet, web-based, or paper questionnaires for measuring anxiety in patients suspected of breast cancer: Patients' preferences and quality of collected data. Journal of Medical Internet Research, 16(10), e239. doi:10.2196/jmir.3578 PMID:25364951

Bravo, C., O’Donoghue, C., Kaplan, C. P., Luce, J., \& Ozanne, E. (2014). Can mHealth Improve Risk Assessment in Underserved Populations? Acceptability of a Breast Health Questionnaire App in Ethnically Diverse, Older, Low-Income Women. Journal of Health Disparities Research and Practice, 7(4), 6. PMID:25705576

Chaudry, B. M., Connelly, K. H., Siek, K. A., \& Welch, J. L. (2012). Mobile interface design for low-literacy populations. In IHI '12 (p. 91). Academic Press.

Chesser, A. K., Keene Woods, N., Wipperman, J., Wilson, R., \& Dong, F. (2014). Health Literacy Assessment of the STOFHLA: Paper Versus Electronic Administration Continuation Study. Health Education \& Behavior, 41(1), 19-24. doi:10.1177/1090198113477422 PMID:23444322

Elson, S. L., Hiatt, R. A., Anton-Culver, H., Howell, L. P., Naeim, A., Parker, B. A., van't Veer, L. J., Hogarth, M., Pierce, J. P., DuWors, R. J., Hajopoulos, K., \& Esserman, L. J. (2013). The Athena Breast Health Network: Developing a rapid learning system in breast cancer prevention, screening, treatment, and care. Breast Cancer Research and Treatment, 140(2), 417-425. doi:10.1007/s10549-013-2612-0 PMID:23887672

Emsley, R., Liu, H., Emsley, R., \& Liu, H. (2013). PARAMED: Stata module to perform causal mediation analysis using parametric regression models. Academic Press.

Cancer Facts \& Figures for Hispanics/Latinos 2015-2017. (2017). Academic Press.

Fromme, E. K., Kenworthy-Heinige, T., \& Hribar, M. (2011). Developing an easy-to-use tablet computer application for assessing patient-reported outcomes in patients with cancer. Supportive Care in Cancer : Official Journal of the Multinational Association of Supportive Care in Cancer, 19(6), 815-822. doi:10.1007/s00520010-0905-y PMID:20512360

Goel, M. S., Brown, T. L., Williams, A., Cooper, A. J., Hasnain-Wynia, R., \& Baker, D. W. (2011). Patient reported barriers to enrolling in a patient portal. Journal of the American Medical Informatics Association, 18(Supplement 1), i8-i12. doi:10.1136/amiajnl-2011-000473 PMID:22071530

Goel, M. S., Brown, T. L., Williams, A., Hasnain-Wynia, R., Thompson, J. A., \& Baker, D. W. (2011). Disparities in Enrollment and Use of an Electronic Patient Portal. Journal of General Internal Medicine, 26(10), 1112-1116. doi:10.1007/s11606-011-1728-3 PMID:21538166

Hahn, E. A., Cella, D., Dobrez, D., Shiomoto, G., Marcus, E., Taylor, S. G., Vohra, M., Chang, C.-H., Wright, B. D., Linacre, J. M., Weiss, B. D., Valenzuela, V., Chiang, H.-L., \& Webster, K. (2004). The talking touchscreen: A new approach to outcomes assessment in low literacy. Psycho-Oncology, 13(2), 86-95. doi:10.1002/pon.719 PMID:14872527 
Kumar, S., Nilsen, W. J., Abernethy, A., Atienza, A., Patrick, K., Pavel, M., Riley, W. T., Shar, A., Spring, B., Spruijt-Metz, D., Hedeker, D., Honavar, V., Kravitz, R., Craig Lefebvre, R., Mohr, D. C., Murphy, S. A., Quinn, C., Shusterman, V., \& Swendeman, D. (2013). Mobile Health Technology Evaluation. American Journal of Preventive Medicine, 45(2), 228-236. doi:10.1016/j.amepre.2013.03.017 PMID:23867031

Lee, S.-Y. D., Bender, D. E., Ruiz, R. E., \& Cho, Y. I. (2006). Development of an Easy-to-Use Spanish Health Literacy Test. Health Services Research, 41(4 Pt 1), 1392-1412. doi:10.1111/j.1475-6773.2006.00532.x PMID:16899014

Levy, H., Janke, A. T., \& Langa, K. M. (2015). Health Literacy and the Digital Divide Among Older Americans. Journal of General Internal Medicine, 30(3), 284-289. doi:10.1007/s11606-014-3069-5 PMID:25387437

Lin, C. A., Neafsey, P. J., \& Strickler, Z. (2009). Usability testing by older adults of a computer-mediated health communication program. Journal of Health Communication, 14(2), 102-118. doi:10.1080/10810730802659095 PMID:19283536

Lofland, J. H., Schaffer, M., \& Goldfarb, N. (2000). Evaluating health-related quality of life: Cost comparison of computerized touch-screen technology and traditional paper systems. Pharmacotherapy, 20(11), 1390-1395. doi:10.1592/phco.20.17.1390.34887 PMID:11079288

Medhi, I., Gautama, S. N. N., \& Thies, W. (2011). Designing Mobile Interfaces for Novice and Low-Literacy Users. ACM Transactions on Computer-Human Interaction, 18(28), 1-28. doi:10.1145/1959022.1959024

Murff, H. J., Byrne, D., Haas, J. S., Puopolo, A. L., \& Brennan, T. A. (2005). Race and family history assessment for breast cancer. Journal of General Internal Medicine, 20(1), 75-80. doi:10.1111/j.1525-1497.2004.40112.x PMID:15693932

Qureshi, N., Brenda Wilson, D., Pasqualina Santaguida, F., Carroll, J., Judith Allanson, F., Carolina Ruiz Culebro, D., ... Raina, P. (2007). Collection and Use of Cancer Family History in Primary Care. Evid Rep Technol Assess, (159), 1-84.

Rich, E. C., Burke, W., Heaton, C. J., Haga, S., Pinsky, L., Short, M. P., \& Acheson, L. (2004). Reconsidering the family history in primary care. Journal of General Internal Medicine, 19(3), 273-280. doi:10.1111/j.15251497.2004.30401.x PMID:15009784

Sarkar, U., Karter, A. J., Liu, J. Y., Adler, N. E., Nguyen, R., \& Schillinger, D. (2010). The Literacy Divide: Health Literacy and the Use of an Internet- Based Patient Portal in an Integrated Health System-Results from the Diabetes Study of Northern California (DISTANCE). Journal of Health Communication, 15(sup2, Suppl 2), 183-196. doi:10.1080/10810730.2010.499988 PMID:20845203

Sarkar, U., Schillinger, D., López, A., \& Sudore, R. (2011). Validation of Self-Reported Health Literacy Questions Among Diverse English and Spanish-Speaking Populations. Journal of General Internal Medicine, 26(3), 265-271. doi:10.1007/s11606-010-1552-1 PMID:21057882

Silow-Carroll, S., Alteras, T., \& Stepnick, L. (2006). Patient-Centered Care for Underserved Populations: Definition and Best Practices. Washington, DC: Economic and Social Research Institute. Available from: http:// www.esresearch.org/ documents_06/Overview.pdf

Steinhubl, S. R., Muse, E. D., \& Topol, E. J. (2015). The emerging field of mobile health. Science Translational Medicine, 7(283), 283rv3. doi:10.1126/scitranslmed.aaa3487 PMID:25877894

Vargas, P. A., Robles, E., Harris, J., \& Radford, P. (2010). Using information technology to reduce asthma disparities in underserved populations: A pilot study. The Journal of Asthma : Official Journal of the Association for the Care of Asthma, 47(8), 889-894. doi:10.3109/02770903.2010.497887 PMID:20846082

Yarnall, K. S. H., Pollak, K. I., Østbye, T., Krause, K. M., \& Michener, J. L. (2003). Primary Care: Is There Enough Time for Prevention? American Journal of Public Health, 93(4), 635-41. 
Arash Naeim is a Professor of Medicine, UCLA Divisions of Hematology-Oncology and Geriatric Medicine Senior Leader; Director of Informatics, Jonsson Comprehensive Cancer Center; Associate Director, UCLA Clinical Translational Science Institute; Director, Center for SMART Health; and Chief Medical Officer for Clinical Research, UCLA Health Sciences.

Zhuoer Xie is a Physician of Geriatric Medicine and Assistant Project Scientist UCLA David Geffen School of Medicine.

Liliana Johansen is a Project Coordinator at ECRI, Embedded Clinical Research and Innovation Unit, UCLA Clinical and Translational Science Institute.

Neil S. Wenger is Professor of Medicine in the Division of General Internal Medicine in the David Geffen School of Medicine at UCLA.

David Elashoff is a Professor of Medicine, Biostatistics, and Biomathematics; Director, Department of Medicine; and Statistics Core Leader, UCLA CTSI Biostatistics Program.

Antonia Petruse is the Director of Embedded Clinical Research and Innovation Unit, UCLA Clinical and Translational Science Institute.

Guita Rahbar is the Section Chief for Breast Imaging, Olive View-UCLA Medical Center, and Associate Clinical Professor of Radiological Sciences, David Geffen School of Medicine at UCLA. 